\title{
Retraction Note to: Platelet-derived growth factor-D contributes to aggressiveness of breast cancer cells by up-regulating Notch and NF- $\kappa \mathrm{B}$ signaling pathways
}

Aamir Ahmad ${ }^{1}$ Zhiwei Wang ${ }^{1} \cdot$ Dejuan Kong ${ }^{1} \cdot \operatorname{Raza} \mathrm{Ali}^{1} \cdot$ Shadan $\mathrm{Ali}^{2}$ Sanjeev Banerjee ${ }^{1} \cdot$ Fazlul H. Sarkar $^{1}$

Published online: 13 July 2016

(C) Springer Science+Business Media New York 2016

Retraction Note to: Breast Cancer Res Treat (2011) 126:15-25

DOI 10.1007/s10549-010-0883-2

The paper is retracted at the request of the publisher because blots of Figs. 3c and 5a were manipulated and compiled from different films without explanation.

The online version of the original article can be found under doi:10.1007/s10549-010-0883-2.

Fazlul H. Sarkar

fsarkar@med.wayne.edu

1 Department of Pathology, Barbara Ann Karmanos Cancer Center, Wayne State University School of Medicine, 740 HWCRC Bldg, 4100 John R Street, Detroit, MI 48201, USA

2 Department of Internal Medicine, Barbara Ann Karmanos Cancer Center, Wayne State University School of Medicine, Detroit, MI 48201, USA 